[published in Sarina Wakefield (ed.), 2021, Museums of the Arabian Peninsula: Historical Developments and Contemporary Discourses, Abingdon/Oxford: Routledge, pp. 85-104]

\title{
Chapter 6: Cultural Diffusion and its Impact on Heritage Representation in the Kingdom of Bahrain
}

Pierre Lombard and Nadine Boksmati-Fattouh

\author{
http://orcid.org/0000-0002-8452-0630 (Pierre Lombard) \\ https://orcid.org/0000-0001-5020-5264 (Nadine Boksmati-Fattouh)
}

\begin{abstract}
Bahrain's rich past was documented in varied explorers' accounts as early as the $19^{\text {th }}$ century. However, local awareness of the significance of Bahrain's heritage burgeoned in the 1950s following the Moesgard Danish archaeological expedition seminal findings, which revealed concrete evidence of the flourishing of the civilisation of Dilmun on ancient Bahrain. The increasingly growing archaeological discoveries across the island in the following years necessitated the creation of a museum to preserve and showcase the collections. The need for a national museum was supported by the Government of Bahrain as well as local and international organisations. In 1988, the Bahrain National Museum was opened to the public and has since played a vital role in preserving and promoting the nation's archaeological, ethnographic, and artistic heritage. The viability of the National Museum comes to the fore today as a result of a cultural diffusion policy that was endorsed by the Bahrain Authority for Culture and Antiquities in 2006. The resulting network of site museums and visitors' centres across the island have produced varied narratives reflecting a shift in cultural policies in Bahrain. This chapter examines the impact and ramifications of the proliferation of archaeological museums in Bahrain and the challenges it presents for the future of the National Museum and its core mission.
\end{abstract}

\section{Introduction: The National Narrative}

The creation of the Bahrain National Museum, like most other Gulf States' museums, was associated with the manifestation of national identity and the notion of nationhood (ErskineLoftus, 2010: 20; 2016: 75-79; Bouchenaki, 2011; 2016; Aubry, 2013; Wakefield, 2015; Exell and Wakefield, 2016). This state initiative, endorsed by the rulers of Bahrain, was integral to the building of a modern state and was clearly aimed at constructing a national narrative to instil and reinforce a sense of communal identity. In fact, the initial project proposal for the Bahrain National Museum was envisaged as a 'Civic Centre Complex' that would include a national museum, a congress complex, a library, a planetarium, and an aquarium (Tjahjono, 1995; Vine, 1993: 2). Notably, and in line with Anderson's (2006) discussion in his book 'Imagined Communities', Bahrain's longstanding past and rich culture was employed by the state as a vehicle for 'imagining' and constructing new representations of the Bahraini society. This culturally imbued image was at the core of national policies as it was deemed instrumental for the building of 'modern' Bahrain. There is no doubt that the creation of a national museum was central to the formation and assertion of a distinct national identity in the way it defined and consolidated the link with a pre-Islamic past and produced self-representations of Bahrain and its 
people. Along this line, the Bahrain National Museum became the repository and primary generator of a Bahraini collective identity and similarly served as an apparatus for the propagation of the state's cultural policy (see Aronsson, 2011; Harrison, 2013). However, despite the inherent political motives of the Government of Bahrain at that time, it is important to emphasise that the particularities of the establishment of the Bahrain National Museum are different from its neighbouring Gulf States and should be examined it its own context. In what follows, we argue that the creation of the Bahrain National Museum also developed as a necessity to protect and preserve a cultural heritage considered at risk of destruction - as a result of the rapid urbanisation of the country -, a specificity that shaped museum practice in the years that followed.

Unlike Saudi Arabia, Kuwait, Qatar and the United Arab Emirates, evidence for the occupation of the island of Bahrain prior to the late third millennium BCE is relatively modest (Potts, 1990: 29-53). This dearth of material culture is counterbalanced by abundant evidence from the Bronze Age period. It was during this time that Bahrain became c. $2050 \mathrm{BCE}$, the political and economic centre of Dilmun, an outstanding trade emporium on the crossroads of ancient trade (Lombard, 2016a: 124-128). The strategic location of Bahrain between Mesopotamia and the Indus Valley and its natural wealth in sweet water and pearl fisheries have laid the foundation for a vital harbour and market place in the Arabian Gulf, and ultimately dictated the cultural development of Bahrain and its people throughout the ages.

Bahrain's rich and diverse cultural heritage has captured the attention of explorers since the $19^{\text {th }}$ century as attested in their accounts and illustrated diaries (Durand, 1880; André-Salvini, 1999: 16-17; Chevalier, 1999; Rice, 1984: 10-11, 29-36; Brisch, 2010; Laursen, 2017). In 1879, the discovery of a basalt stone with a cuneiform inscription by Captain E.L. Durand, a British officer and amateur archaeologist stationed in Bahrain, brought Bahrain to the attention of international academics and prompted several archaeological explorations (Rawlinson, 1880). The year 1953 marked the arrival of the Danish archaeological expedition ${ }^{1}$ to Bahrain and put an end to decades of sporadic archaeological work on the island. Discoveries at the site of Qal'at alBahrain and the temples of Barbar provided evidence of the flourishing trade networks of the civilisation of Dilmun and established the historical importance of Bahrain (Lombard and AlSindi, 1999: 22-27; Højlund, 2007: 123-136; Maclean and Insoll, 2011: 72-79; Lombard, 2016a: 124-128; Laursen, 2017: 379-384). The results of the first seasons of the Danish excavations were exhibited at Al-Hidaya Al-Khalifia School in Muharraq in 1957. The exhibition was meant to engage the local community with the latest archaeological results and foster local awareness. But most importantly, it presented the pre-Islamic heritage of Bahrain to the public for the first time (Vine, 1993: 2). This first public display was an important milestone in the history of museum creation in Bahrain in the way it prompted for the first-time discussions about heritage preservation and presentations among international experts and locals, including the ruler of 
Bahrain. The Late Amir Shaikh Salman Bin Hamad Al-Khalifa was a strong advocate of heritage preservation and one of the main sponsors of the excavations (Figures 1 and 2).

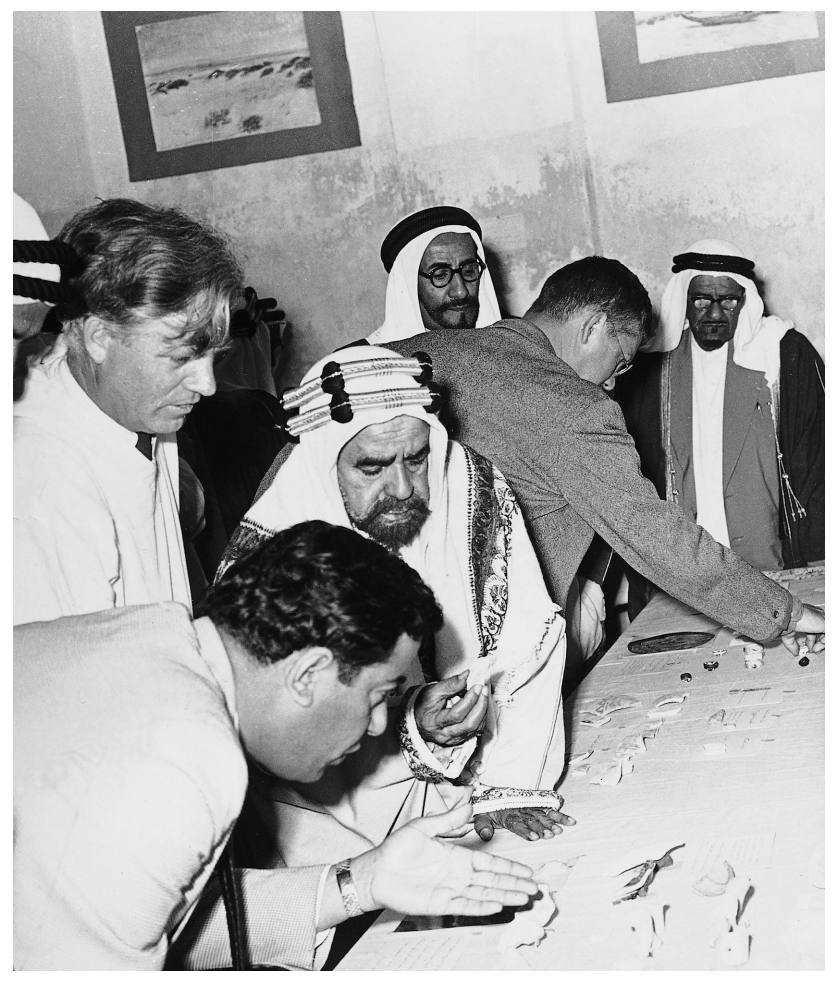

Figure 1 - Shaikh Salman bin Hamad Al-Khalifa visiting the display at Al-Hidaya Al-Khalifa School

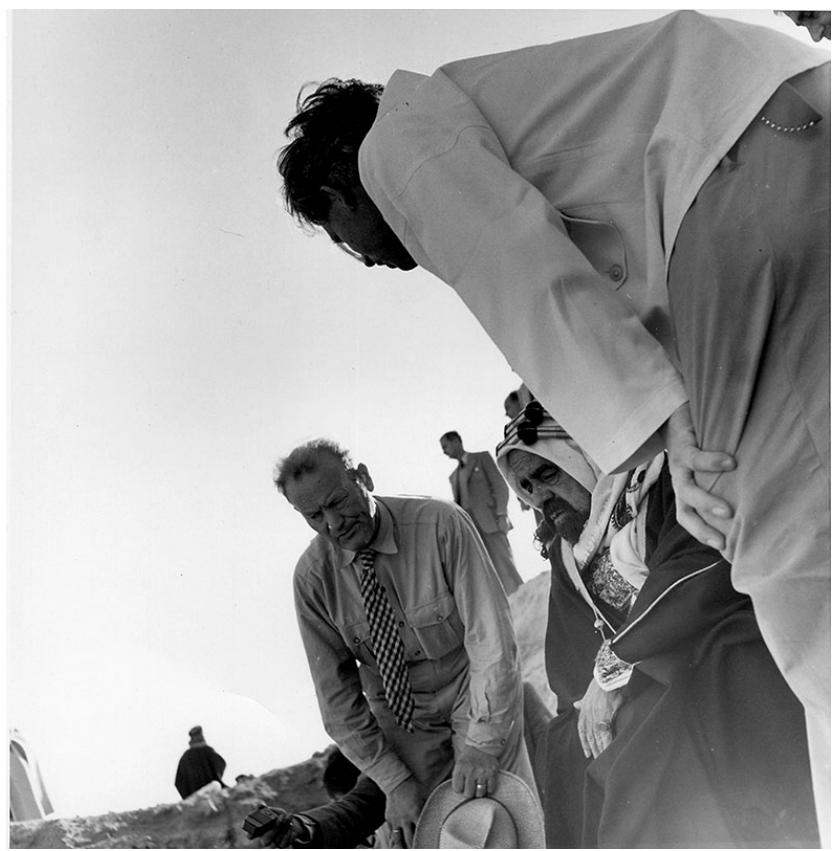

Figure 2 - Shaikh Salman bin Hamad Al-Khalifa visiting the Danish archaeological excavations 
The momentum and public interest garnered by the aforementioned archaeological display at Al-Hidaya Al-Khalifia School slightly waned as the Danish expedition did not keep up with presenting their results at the end of the following excavation seasons. However, the modernisation of the state of Bahrain in the late 1960s and early 1970s brought heritage discussions back to the fore. Given the small geographic area of Bahrain - roughly $700 \mathrm{~km}^{2}$ - and the wealth and density of its archaeological heritage, some urban projects were halted by archaeological findings raising growing concerns among the local and the international community regarding the safeguarding of the heritage of Bahrain. This specificity galvanised a sense of national consciousness that was cultivated by international scholars working in Bahrain and supported by the Bahrain Historical and Archaeological Society ${ }^{2}$. As the Government of Bahrain was faced with the need to organise the rescue excavations, create a framework for the study of the excavated material, and the storage and public presentation of the recurrent new discoveries, a formal request was sent to UNESCO to seek professional assistance (Vine, 1993: 2).

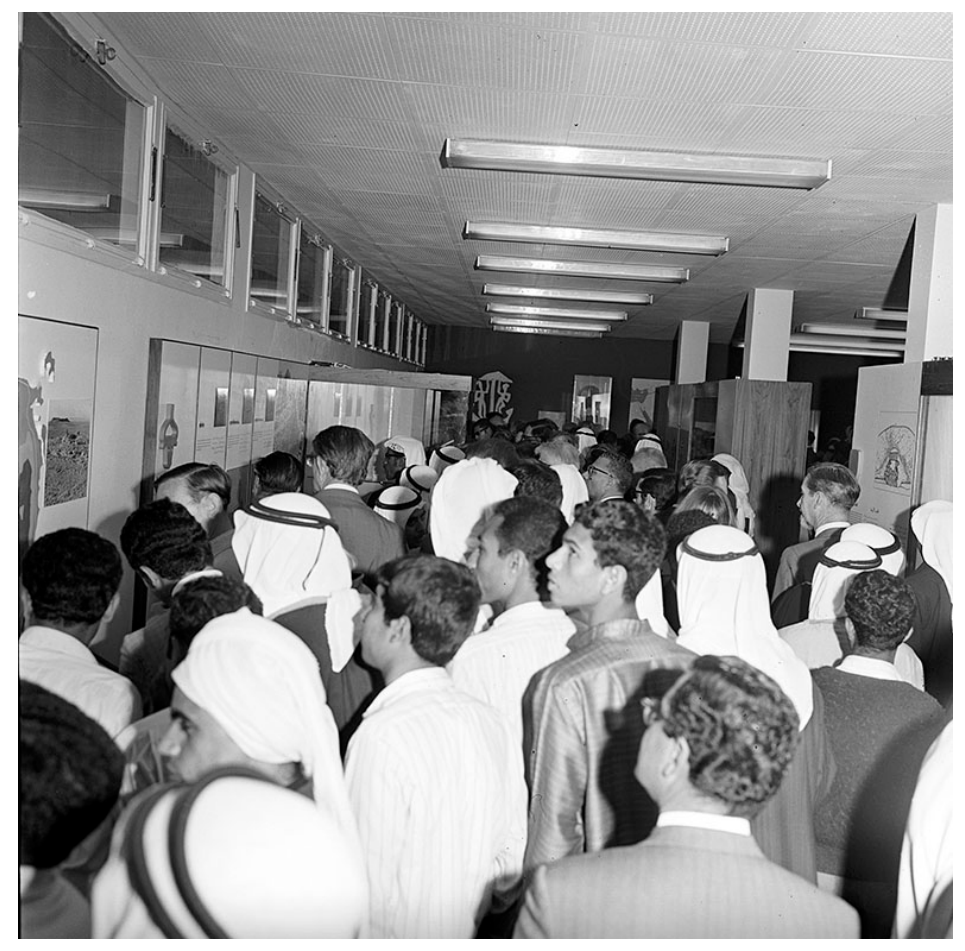

Figure 3 - Opening of Bahrain's first permanent display in Manama

In 1967, the Government of Bahrain signed a cultural policy agreement with UNESCO that defined the guidelines for a long-term collaboration according to which the international organisation would provide the knowledge and expertise to assist Bahrain in assessing and managing its heritage. Consequently, a report was submitted to the Government of Bahrain in 1968 that highly recommended the drafting of a law of antiquities and the establishment of a national museum (Ghosh, 1968). In the months that followed, the establishment of a Bahraini Department of Antiquities under the auspices of the Ministry of Education formalised heritage 
preservation in Bahrain. In 1969, the first Bahraini team of excavators was formed and in 1970 the first 'Law of Archaeology' was implemented. Thereafter, the Government of Bahrain sought the scientific guidance of archaeologist G. Bibby to prepare a display at the Government House in Manama. Eventually, Bahrain's first permanent exhibition, designed by architect M. Rice, was opened in March 1970 to coincide with the hosting of the Third International Conference of Asian Archaeology in Bahrain (Figures 3 and 4). In addition, the government allocated significant budgets for the preservation of archaeological sites, the restoration of historic houses, the hosting of international conferences, and for academic research (Al-Khalifa and Rice, 1986: 10-14). This cultural investment at the time was a momentous step aimed at enhancing the image of Bahrain as a civilized and modern nation-state and, consequently, boosting its potential to become a main touristic destination in the region.

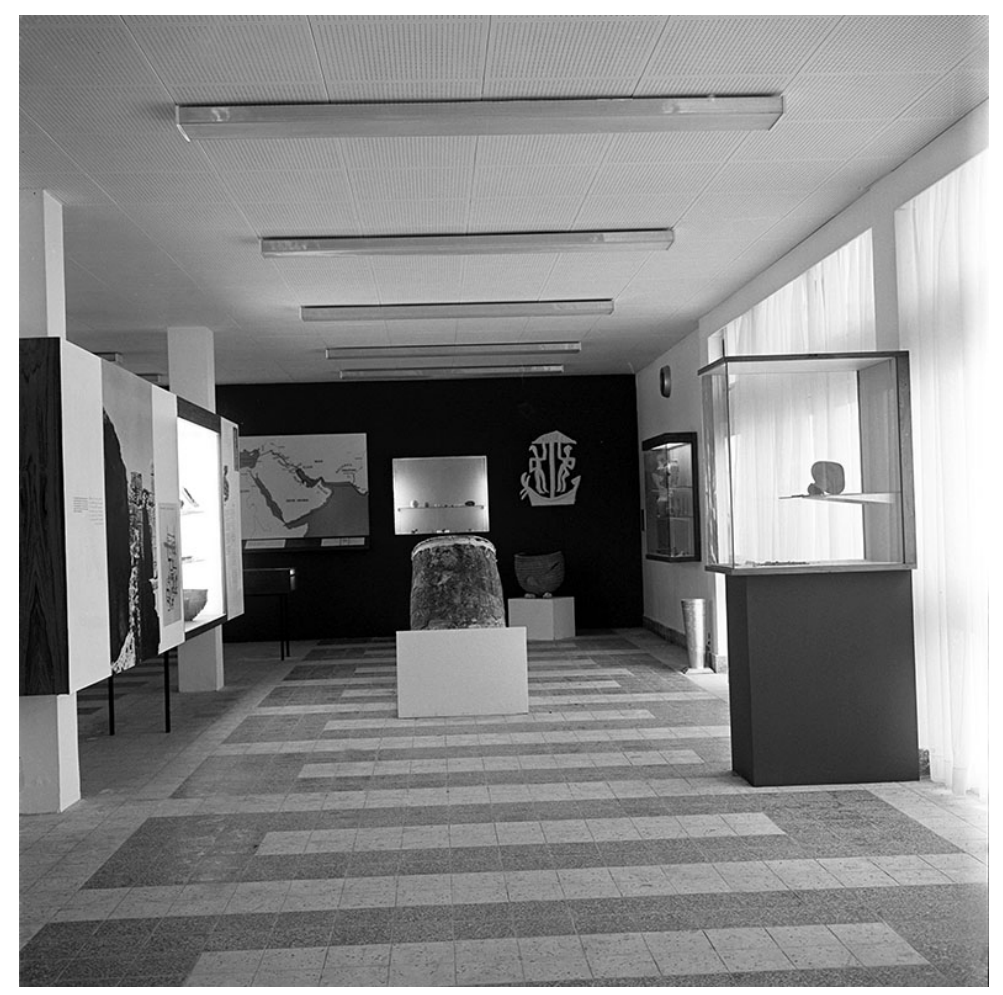

Figure 4 - Bahrain's first permanent display designed by M. Rice

The museum quickly became too small to house the collections as a result of continued archaeological interventions and amassing findings. The exhibition was hence moved in 1973 to the former British Royal Air force headquarters in Muharraq. The new display was curated and designed to illustrate Bahrain's rich and diverse past. It was laid out in five thematic galleries that featured the country's ancient history, traditions and geology (Champault, 1979, Vine, 1993: 2-3, Musameh, 2004). The new location served as an interim museum and active centre for education as revealed in several reports exchanged between staff and the director of the 
museum ${ }^{3}$. Concurrently, the government was investigating developing an ambitious museum project to preserve and display Bahrain's growing collections.

Following an international competition, the Government of Bahrain selected a design for a new national museum submitted by Danish KHRAS Arkitekter's (architects Knud Holscher and Sven Axelsson). The proposed design adapted local and Islamic architectural traditions, which were mainly reflected in the building's simple geometric shapes and facades as well as the courtyard and the pools of fresh water. The project also considered the nature and diversity of local collections and their conservation requirements and included, what was considered at the time, advanced climatic and security control systems (Holscher, 1990, Musameh, 1999: 32). In 1982, the Danish architects were commissioned along with local engineering firm Cowiconsult to implement the design and supervise the building of the new national museum. After considering several locations for the new building, the government allocated a reclaimed plot of land on a strategic seafront site at the intersection of two major highways linking the old city of Muharraq with the new town centre (Vine, 1993: 5; Musameh, 2004: 14). On December 15, 1988, the Bahrain National Museum was inaugurated on the occasion of the country's national day in a ceremony under the patronage and attendance of the Amir of Bahrain.

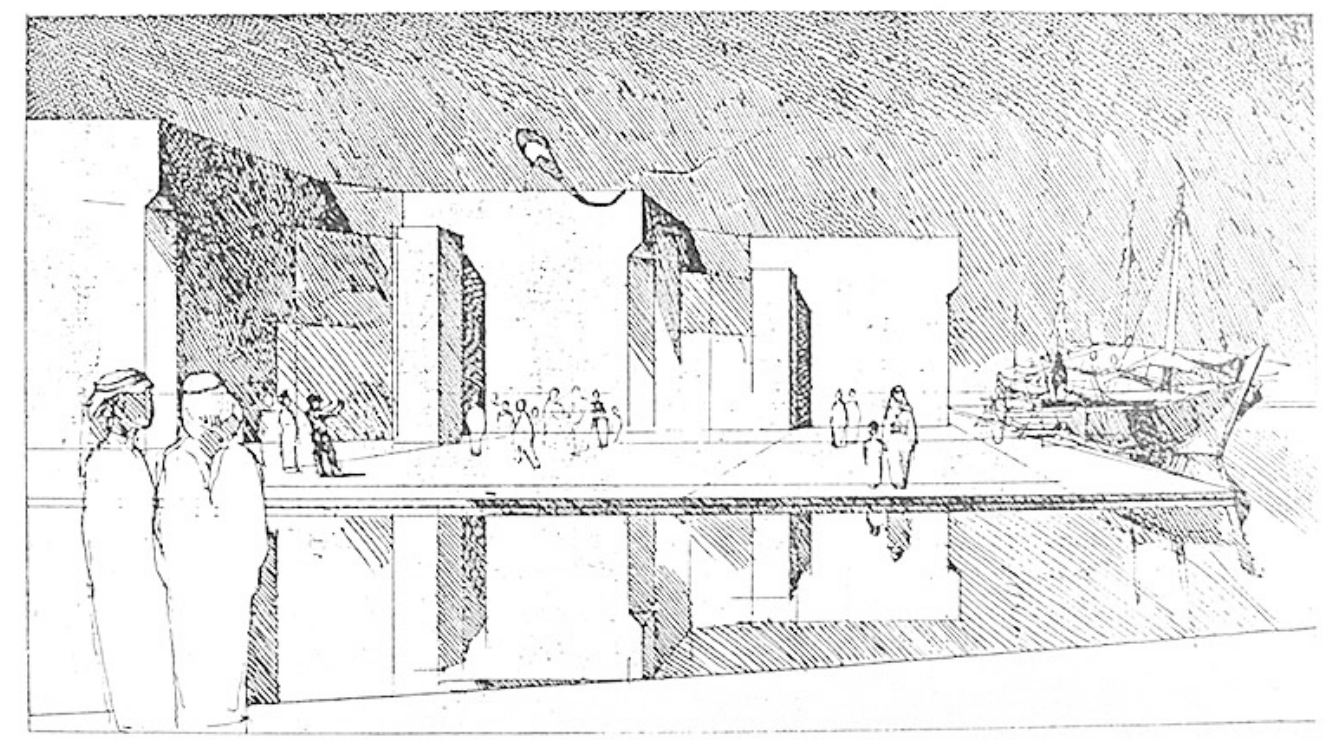

Figure 5 - Bahrain National Museum. Original sketch by Thorkild Ebert

The 22,400 $\mathrm{m}^{2}$ landmark building (Figures 5 and 6), characterised by its simple cubic shapes and travertine façades, included $3250 \mathrm{~m}^{2}$ of exhibition space. The latter were organised chronologically and thematically and featured a distinctive selection of Bahrain's archaeological, ethnographic, historic and art collections. It was considered at the time to be the first museum of its kind in the Arabian Gulf due to its large scale, the adopted exhibition standards - maintenance of climatic conditions and safety requirements - in addition to the equipped curatorial, conservation and research facilities it included. Significantly, the new institution was innovative 
in regards to its conceptual foundation that underscores the social role of the museum. Beyond its distinctive architectural design and exhibition scenography, the project's objective was to build

a new place for the public to appreciate culture, art and reading, which acts as a landmark of Manama, to house and exhibit the rich cultural heritage of Bahrain, to educate Bahrainis to appreciate their own culture, and to popularise museums as centres of social communications.

Tjahjono, 1995

Notably, the museum's envisaged role transcends the preservation of the collections to building a sense of place. Eventually, and with the guidance of the International Council of Museums (ICOM), the organisational framework, mission, and programme directives were defined. The Bahrain National Museum channelled western practice and policies or, as Smith (2006) argues, an 'Authorised Heritage Discourse' that was defined by national and international agencies such as UNESCO and ICOM. However, despite the general operational guidelines, the close involvement of Bahraini stakeholders in the preparation, designing, and implementation of the architectural concept and the museum program, insured that the new museum meets the conservation and presentation requirements of the collections and responded to the needs of the local communities (Musameh, 1999: 61-70). More importantly, the Bahrain National Museum was managed and operated by an overwhelmingly Bahraini team, who either received training abroad or on the job, and insured that the museum meets global museum practice and fulfils its mission.

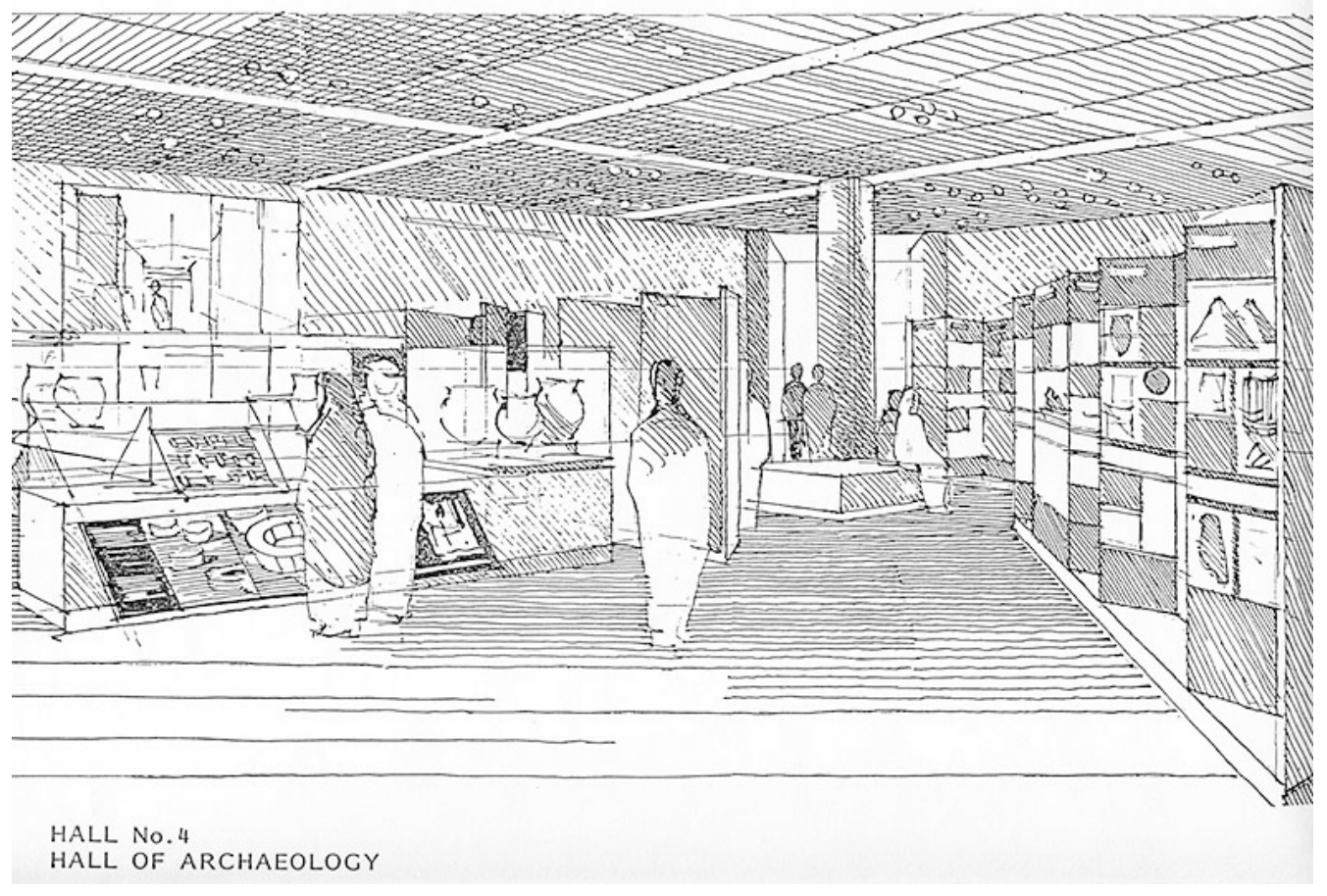

Figure 6 - Hall of Archaeology at the Bahrain National Museum. Original sketch by Thorkild Ebert 
The mission statement solidified the diversity and centrality of the local collections and defined the museum's role as an educational resource and research centre:

The Bahrain National Museum is a non-profit, educational and scientific organisation. Its main purpose is to preserve, increase and disseminate knowledge of the artistic, natural and cultural history of Bahrain. The Museum fulfils these objectives by collecting, preserving, studying, interpreting and utilising tangible objects in programmes of exhibitions, education or research.

(Vine, 1993: 6)

Arguably, following the Bahrain National Museum served as a vital 'educative apparatus' (Harrison, 2013) for the Government of Bahrain to channel the country's cultural policy and promote the state's narrative through formal and informal educational programming, exhibitions and public events. Visitors figures for the museum's first ten years of operation are indicative of its popularity among local and international visitors and the engagement of Bahrainis with their heritage (Musameh, 1999: 90). In particular, the diverse outreach programming and the regular hosting of acclaimed international exhibitions helped maintain high visitation patterns over the year. The opening of the Natural History Hall in December 1993 and the hosting of a dinosaur exhibition Dino-life in September 1994 produced the second highest number of visitors to date ${ }^{4}$.

\section{New Approaches to Heritage Presentation and Representation}

In the wake of an unprecedented investment in the cultural industries in the Arabian Gulf, the Bahrain Authority for Culture and Antiquities ${ }^{5}$ (BACA) began to further diversify and promote the nation's local heritage with the aim of positioning itself as a regional cultural hub.

Notably, BACA devised a long-term strategy that focused on building a sustainable cultural infrastructure to ensure the protection, preservation, and transmission of Bahrain's local heritage in all its forms. Bahrain's millennia-old archaeological heritage, deemed the country's most 'authentic' cultural component and an important particularity that distinguished it from its GCC neighbours, was inherently reinforced and used as the main marketing tool locally and internationally (cf Pillars of Culture, 2016). In addition to prioritising the inscription of a number of sites on UNESCO's World Heritage list, BACA supported a cultural diffusion policy which was manifested in the creation of a network of site museums and visitors' centres across the island (Figure 7) and the organisation of several international travelling exhibitions ${ }^{6}$. 


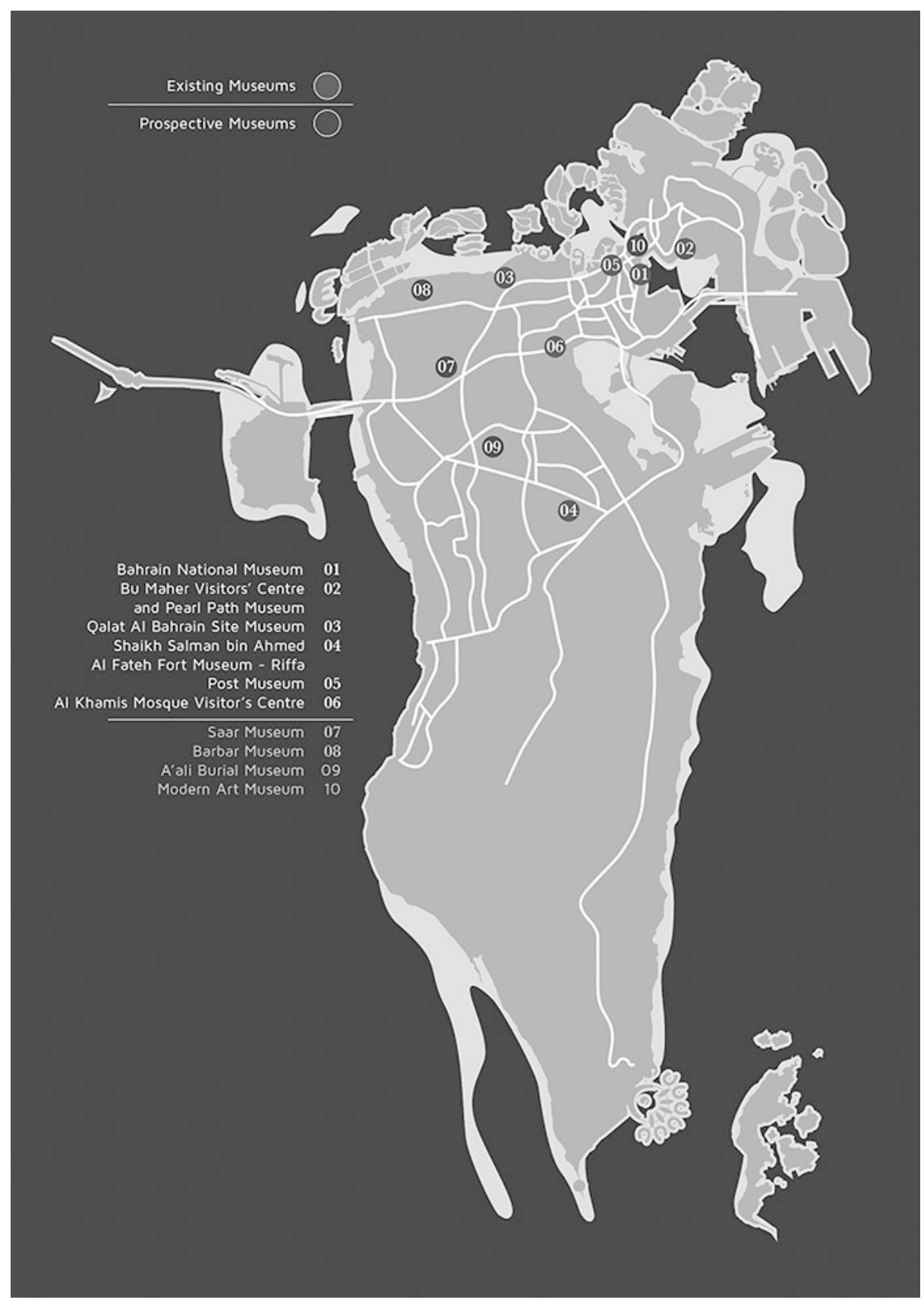

Figure 7 - Map of Bahrain illustrating the network of existing and future museums

In contrast to the planned large-scale projects in neighbouring GCC countries, the creation of multiple contextualised small museums created a 'niche' for Bahrain and provided international exposure (Aubry, 2013; Wakefield, 2015; Al-Sayeh, 2018).

In 2005, the inscription of the archaeological site of Qal'at al-Bahrain on the UNESCO World Heritage list constituted the first milestone in the implementation of the aforementioned strategy and a turning point in the restructuring of the museum department in Bahrain. Indeed, at 
the time of the preparation of the site nomination file, the President of BACA Shaikha Mai bint Mohammed Al-Khalifa (then Assistant Undersecretary for the Culture and National Heritage Sector at the Ministry of Information), called for the inclusion of a site museum as part of the project proposal for the site of Qal'at al-Bahrain. Shortly after, architect Claus Wohlert (Wolhert Arkiteckter) was contacted to prepare an architectural concept. This choice was mainly based on the experience of the architect in museum building and, particularly, his design of the visitor's centre of the UNESCO World Heritage Jelling Monuments (cf Lombard, 2016b).

The strategic decision to include a site museum for Qal'at al-Bahrain was unintentionally in line with earlier recommendations by UNESCO heritage experts following their visit to Bahrain. The 1980 report advocated the creation of a 'series of small site museums built gradually to present all available material and information associated with the site' (Saidah and Lewcock, 1980: 7). Eventually, the inception of Qal'at al-Bahrain Site Museum ${ }^{7}$ paved the way for the systematic implementation of site museums for all the main archaeological and historic sites. Spearheaded by BACA and with the support of public and private funds ${ }^{8}$, a number of projects were completed:

- Qal'at al-Bahrain Site Museum (2008) (Figure 8),

- Al-Rifaa Fort Permanent Exhibition (2012),

- Tree of Life Visitors' Centre (2013),

- Bu Maher Visitors' Centre (2013),

- Postal Building Permanent Exhibition (2015),

- Al-Khamis Mosque Visitors' Centre (2017) (Figure 9),

- Archaeology of Green Pavilion (2018)

- Pearling Path Interpretation and Visitors' Centre (2018).

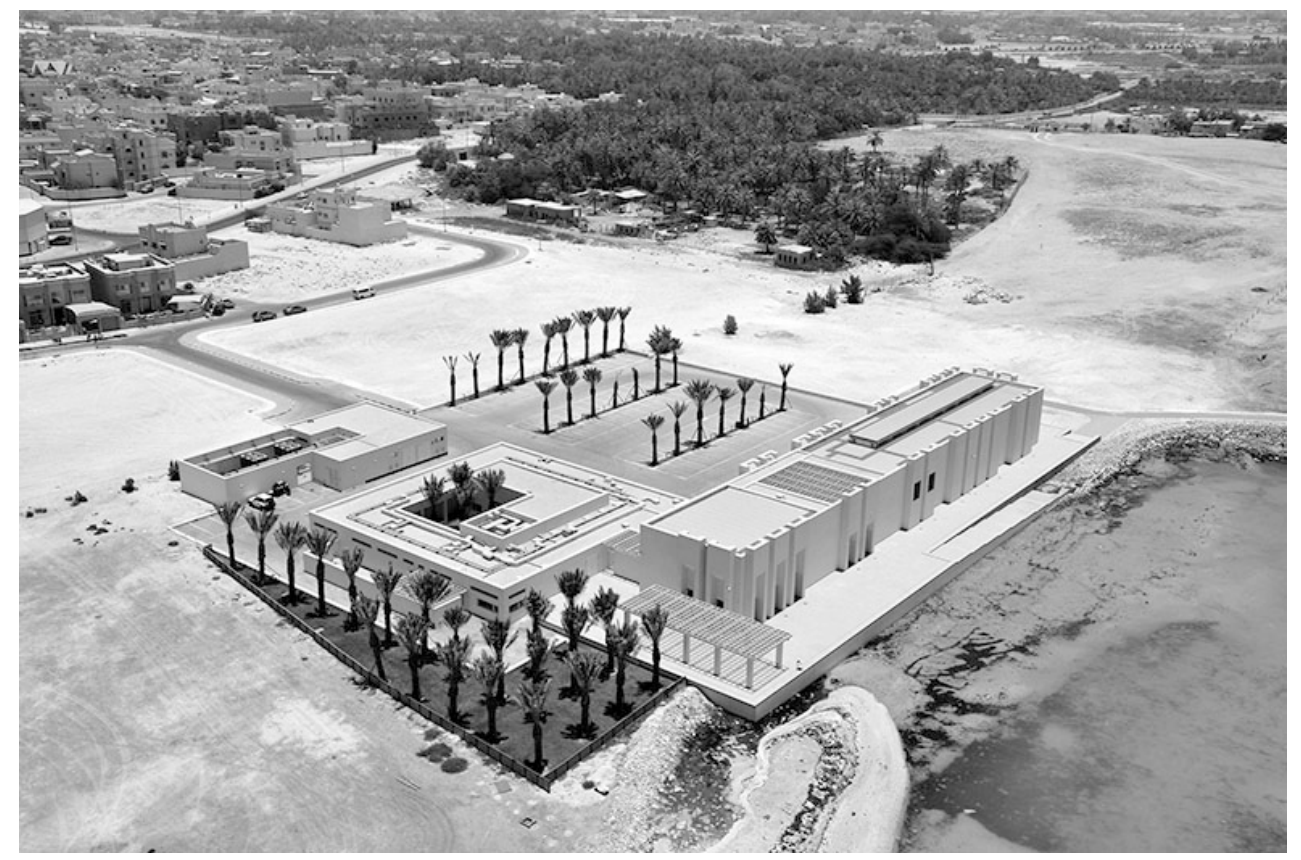

Figure 8-Qal'at al-Bahrain Site Museum 


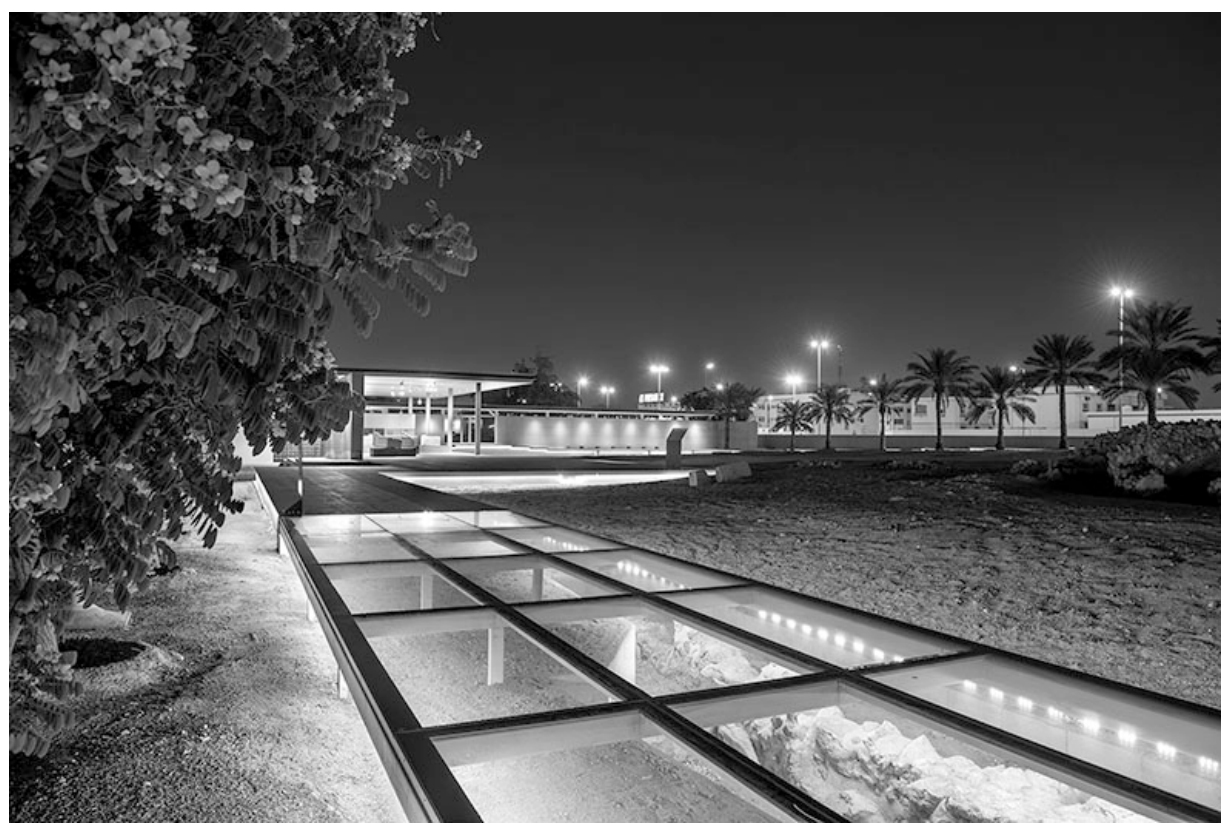

Figure 9 - Al-Khamis Visitors' Centre

At the time of writing, more site museums were slated for development such as the research centre and site museum at the archaeological site of Saar (designed by Tadao Ando Architect \& Associates), the site museum at the A'ali Burial Mounds (designed by Wohlert Arkiteckter) and the site museum at the site of Barbar (designed by Basmaji \& Bielinska Architects). In addition, further developments within the museum sector include the planned Contemporary Art Museum (designed by Zaha Hadid) and the Children's Museum (designed by Fares \& Fares) (Bahrain Authority for Culture \& Antiquities, 2016). The initial architectural designs for the above mentioned museum projects were prepared in the years between 2006 and 2010 (Bahrain Authority for Culture \& Antiquities, 2015). The projects have not been executed yet due to lack of funding.

The specificity of museum diffusion in Bahrain and its originality relates to the relatively modest scale of the museums, the pace in the execution of the projects, and their concentration in a small geographic area. At first glance, those satellite museums, with the Bahrain National Museum as the central node, produce multiple showcases for Bahrain's rich history and raise awareness of endangered archaeological sites. Following Dexter Lord and Blankenberg's argument that 'the very presence of museums signifies that a city is proud of its culture', it is certain that in the case of Bahrain those state-led site museums and visitors' centres are 'signifiers of pride' and do project an image of a community proud of its past (2015: 20). In what follows, we will attempt to touch on some of the impacts of this cultural diffusion and its implications on the viability and performance of the Bahrain National Museum. 


\section{Towards De-centralisation}

The proliferation of site museums and visitors' centres and their focused and contextualised interpretation of local heritage, aimed to provide an in-depth interpretation of the different archaeological periods and historic traditions in Bahrain. This diffusion approach helped to enhance the visibility of the sites, both locally and internationally - and channelled BACA's policy in positioning Bahrain as a main destination for cultural tourism. But also, those museums reflect a certain change in cultural policies in the way local heritage is curated and presented. Mainly, the multiplicity of narratives and representations was intended to represent the diversity of local communities and the complexity of Bahraini societies past and present as illustrated in Al-Khamis Visitors' Centre (Maclean and Insoll, 2014). Moving from the stance that national museums use their collections and displays to articulate the institution's national values and realities (Aronsson, 2011: 117-124), Bahrain's site museums have the potential to negotiate those preset 'realities' through their multiple interpretations. However, this comes at a risk of de-constructing Bahrain National Museum's narrative and challenging its content and viability. Although the Bahrain National Museum's collection storages abound with archaeological material, preparing the content for the different site museums has been laden with challenges.

The development of Qal'at al-Bahrain Site Museum was dominated by contentious discussions among museum management regarding the purpose, function and content of the proposed museum. The discussions touched on various presentation forms and possibilities and emphasised the curators' concern to duplicate some information that is already displayed at the Bahrain National Museum. However, as the excavations on the site of Qal'at al-Bahrain conducted by the French archaeological mission have continued without interruption for decades, there was abundant archaeological material to display, new interpretations to present, and many stories to tell. With the exception of few artefacts (20 out of the exhibited 500 artefacts), the displays at Qal'at al-Bahrain Site Museum were mostly selected from the collection storages of the Bahrain National Museum and not retrieved from its permanent exhibition halls (Lombard, 2018). However, major presentation issues will certainly loom large in the future and will dictate the development of the content for the envisaged museums for the archaeological sites of Barbar and the A'ali Burial Mounds. As those sites were excavated prior to the opening of the Bahrain National Museum, most of the findings constitute the highlights of the National Museum's collection on display. Similarly, the recurrent travelling exhibitions and international contributions have created major challenges for BACA. Over the years, the Bahrain National has continued to explore new communication modes and platforms to broaden its outreach and connect with local communities and international visitors. The presentation and re-interpretation of the collection was deemed instrumental as the displayed narrative and presentation forms in the current exhibits became outdated. In the absence of adequate funding to revamp the Bahrain National Museum's permanent display, different avenues were explored by the museum 
management and curators to engage audiences. In addition to hosting several globally-acclaimed international exhibitions and diverse programming at the museum and beyond its wall, more emphasis was directed towards showcasing and interpreting local collections regionally and internationally. The mobility of the permanent collections in Bahrain and abroad served to showcase the local heritage and encouraged new and alternative layers of interpretations in varied contexts (see Kinoshita, 2014). The circulation of those collections increased the reputation of the Bahrain National Museum and forged significant international cultural networks and valuable partnerships. The major downfall to the mobility of the collections is that very often, emblematic objects are removed from the permanent displays of the museum to be included in travelling exhibitions, which highly impinges on the visitors' experience.

\section{Conclusions}

The diffusion of site museums in Bahrain, and the Gulf in general, has garnered academic attention in recent years and generated some contested discussions (Erskine-Loftus, 2010; 2016; Erskine-Loftus, Hightower and Al-Mulla, 2016; Exell and Wakefield, 2016; Exell and Rico, 2014). While Bahrain's approach was conceived by some as innovative and more 'authentic' (Aubry, 2013), the efficiency of those museums in interpreting local heritage forms can be challenged. The fact that site museums and visitors' centres are state-run raises concerns about the agenda that they serve and their ability to truly voice local communities and represent diverse identities. Those concerns have guided BACA's practice in the last few years as we re-think our approach to heritage presentation and representation and its impact on the well-being of the Bahraini communities.

As more projects are planned in the years to come, it is important to take a step back and critically examine the impact of the proliferation of site museums on the interpretation and representation of local heritage as well as the accessibility and relevance of those museums to the local community. In the absence of in-depth audience research analysis from Bahrain, it is very difficult to determine with accuracy whether those site museums have generated meaningful experiences and produced places where local communities can engage and relate to the past on display. Nevertheless, it is noteworthy to mention here that, based on the authors' personal observations, the Al-Khamis Visitors' Centre has forged a meaningful relation with the local community as reflected by the recurrent presence of community members, who often volunteer to guide the visitors of the site and show their pride in their past. At its inception, Al-Khamis Visitors' Centre was aimed at presenting the Islamic heritage of Bahrain and the past of the area of Bilad Al-Qadeem and its community. Consequently, the content was developed in close collaboration with representatives of the local community and following several interviews with varied members of the community. In particular, one audio installation voiced the memories of elderly community members and their experiences as kids in Bilad Al-Qadeem. Similarly, the 
high attendance of the local community in the neighbourhood of the Qal'at al-Bahrain Site Museum to the museum's activities is a good indicator of the success of the museum's outreach policy. In 2009, a year-long community-based programming was implemented at the site museum, including a children's club, and have been since instrumental in engaging the local community.

It is also important to recognise that varied site museum ventures have drastically changed the urban landscape in Bahrain over the past ten years. All those museums are closely associated with a sense of 'place' and a specific local context, and hence they provide an in-situ interpretation and presentation that is not present at the Bahrain National Museum. This new dimension to the content and presentation generate varied experience for different visitors and could be more meaningful to some. The new architecture, new place, new context(s), and new museographic presentations and multidisciplinary interpretations certainly enhance the visitors' experience and can often create new and different experiences for the visitors of those spaces. With some cultural spaces located within dense urban contexts - especially in the case of the pearling path in Muharraq ${ }^{9}$, their presence has progressively transformed their urban surrounding outside the capital, Manama. As Al-Sayeh (2018) explains, 'the spaces articulate a contemporary local architectural identity that addresses the specifics of the place'. The success of and relevance of this regeneration, as Al-Raouf (2014) argues, is only established by primarily addressing the needs of the local communities. In fact, the creation of cultural spaces has, in addition to providing service facilities to tourists, raised property value, attracted new businesses - mostly cafés and restaurants - and created new employment opportunities. These factors ultimately enhance the quality of life in those areas and help to bring people back to the historic centres.

In regards to the Bahrain National Museum, and despite the repetitive changes in governance and deleterious budget cuts, there has been a clear restructuring in BACA's policies to break down barriers and enhance the museum's accessibility, inclusiveness and participatory roles (Boksmati-Fattouh, 2016). As the permanent displays of the Bahrain National Museum are outdated and are no longer representative of Bahrain's past and present, the museum's curatorial team has tapped into new presentation forms and media and adopted multidisciplinary approaches. The latter have allowed for alternative interpretations of the collections and paved the way for more grounded connections and conversations with local communities. The completion of the remodelling of one of the National Museum's permanent displays - the Hall of Dilmun Graves - in June 2018, sought to provide a more enhanced and engaging museum experience (Figures 10 and 11). 


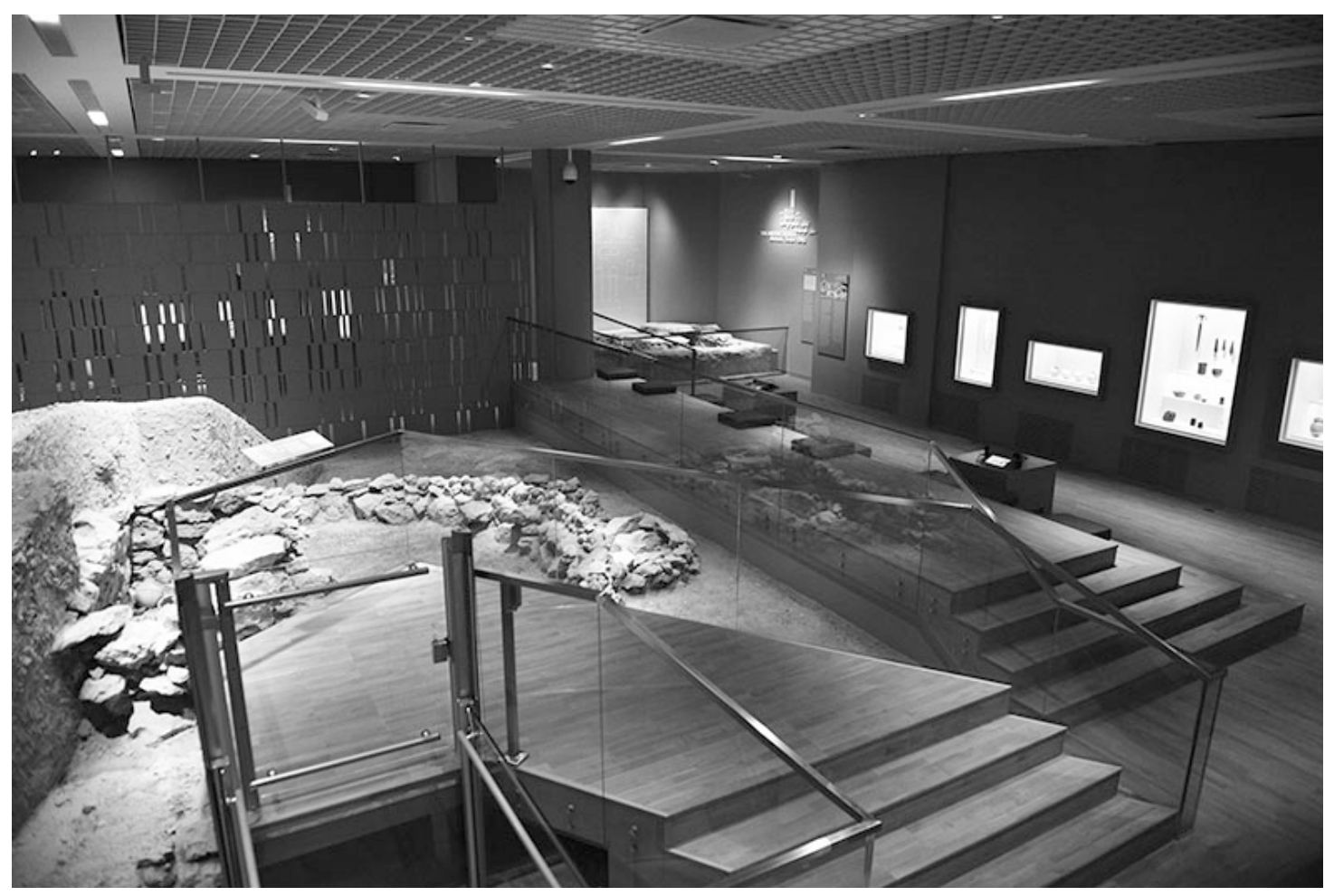

Figure 10 -The remodelled Hall of Dilmun Graves at the Bahrain National Museum

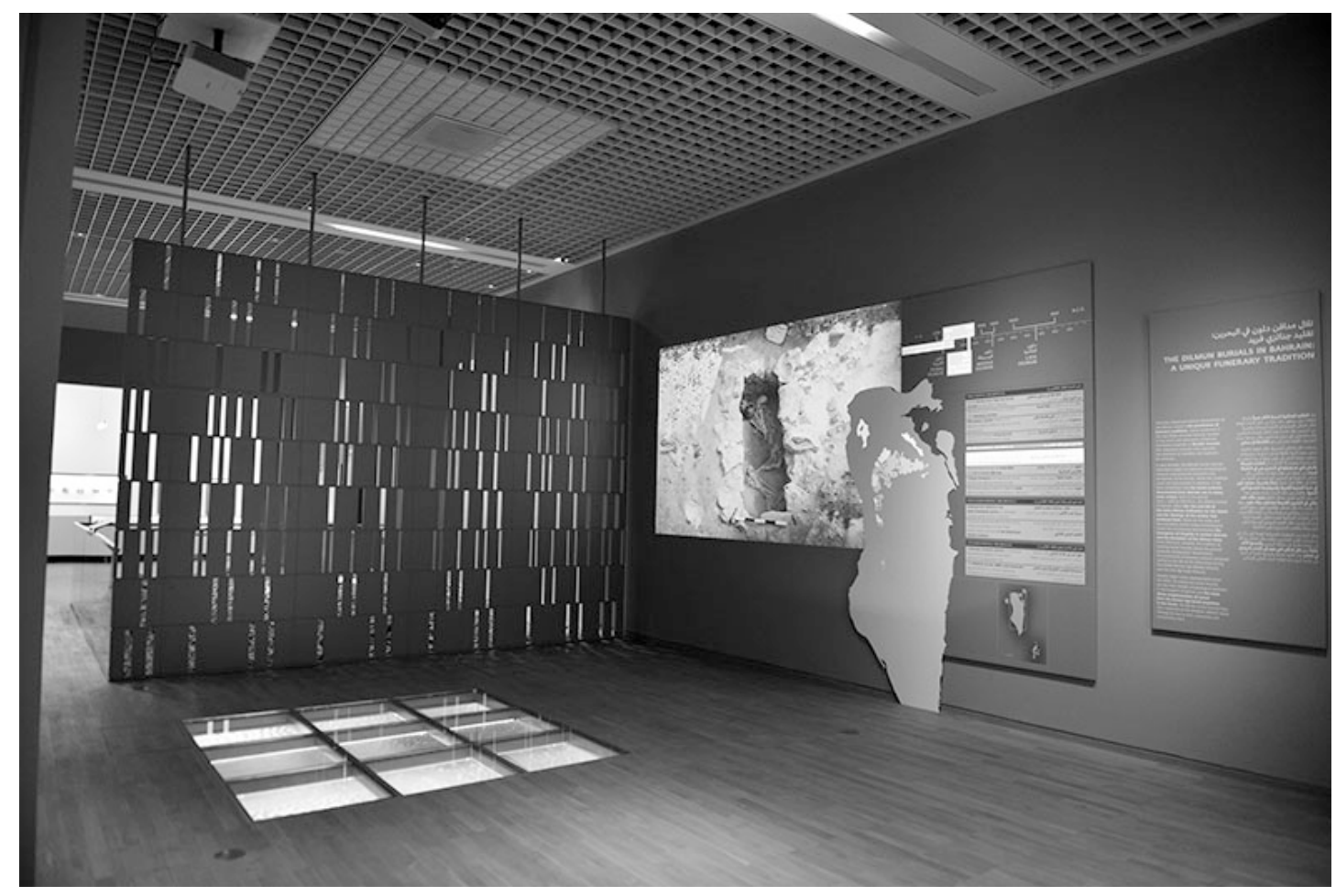

Figure 11 - The remodelled Hall of Graves opened to the public in June 2019 
The adopted multidisciplinary curatorial approach was guided by the need to include several layers of interpretations, enhance storytelling and above all include local voices. The new presentation allows for a comprehensive understanding of the Dilmun burial traditions and their socio-cultural implications both past and present. The Dilmun burial mounds of Bahrain have dominated the island's landscape for millennia and were an integral component of the nation's urban and social fabric. Despite its established significance, nationally and internationally, this area of heritage is contested by the local community as some Bahrainis do not see the need to preserve them, while others consider the burials a national pride.

Over the past three decades, the Bahrain National Museum has continuously adapted to change and adopted new practice to maintain relevance. In particular, the remarkable development of museums in the Arabian Peninsula in the past 10 years and the creation of mega projects has stimulated a re-structuring of the museum institution in Bahrain and dictated its future trajectory. While some museums in the Arabian Peninsula have opted for an international outreach, the Bahrain National Museum created a niche by gravitating towards a more localised approach that focused on the preservation, interpretation and promotion of its local cultural heritage. However, despite its contemporary and often innovative presentation approaches, the Bahrain National Museum has been at times less nimble than its neighbours to part with its traditional curatorial practice. After several years working at the Museum Department in Bahrain, we have come to the realisation that by incessantly and exclusively focusing on maintaining the link with the distant past, we have partly overlooked the present and issues that might matter more to our audiences. In order to maintain relevance and partake in community building, it is vital to get out of our 'comfort zones' and constantly challenge our curatorial approaches by addressing Bahrain's complex social realities - past and present- and create multivocal exhibitions. 


\section{References}

Al-Khalifa, H. and Rice, M. (eds) (1986). Bahrain through the ages. The archaeology. Abingdon and New York: Routledge.

Al-Raouf, A. (2014). 'The rehabilitation of the Muharraq historic centre, Bahrain: a critical narrative'. In: Exell, K. and Rico, T. (eds). Cultural Heritage in the Arabian Peninsula, Debates, Discourses and Practices. Abingdon and New York: Routledge. pp.173-188.

Al-Sayeh, N. (2018). 'Future Vision for Pearling, Testimony of an Island Economy World Heritage site'. World Heritage, 88: pp.48-53.

Anderson, B. (2006). Imagined Communities. Reflections on the Origin and Spread of Nationalism. London and New York: Verso.

André-Salvini, B. (1999). 'Bahreïn, île des origines ou île d'éternité ?', Dossiers d'Archéologie, Hors-Série 7 (juin 1999): pp.14-19.

Aronsson, P. (2011). 'Identity politics and uses of the past with European national museums'. Nordisk Museologi, n.1: pp.117-127.

Aubry, A. (2013). 'Contextualizing History: Bahrain's Innovative Approach to Museum Creation'. In: Erskine-Loftus, P. (ed.). Reimagining Museums: Practice in the Arabian Peninsula. 1st edition Edinburg: MuseumsEtc. pp.66-97.

Bahrain Authority for Culture \& Antiquities. (2015). 'Infrastructure Projects'. (Online) Available at http://www.culture.gov.bh/en/authority/infra projects/ [Accessed 23 January 2020].

Bahrain Authority for Culture \& Antiquities. (2016). Pillars of Culture. Future Strategies. Manama: Bahrain Authority for Culture and Antiquities.

Boksmati-Fattouh, N. (2016). 'Bahrain museums: major strides towards audience inclusion'. In: Pillars of Culture. Future Strategies. Bahrain Authority for Culture and Antiquities, Manama, pp.59-65.

Bouchenaki, M. (2011). 'The extraordinary development of museums in the Gulf States'. Museum International, 63 (3-4, September - December): pp.93-104. 
Bouchenaki, M. (2016). 'Making museums in the Arabian Peninsula'. In: Exell, K. and Wakefield, S. (eds). Museums in Arabia. Transnational Practices and Regional Processes. Routledge: London. pp. xv - xvii.

Brisch, G. (2010). The Travel Chronicles of Mrs J. Theodore Bent. Oxford: Archaeopress.

Champault, D. (1979). Notes sur un projet de musée d'éthnographie. Unpublished Report.

Ghosh, A. (1968). Protection of Cultural Property and Development of a Museum in Bahrain. Restricted Report $\mathrm{n}^{\circ}$ 787/BMS.RD/CLT, UNESCO, Paris.

Chevalier, N. (1999). 'The Rediscovery of a Civilization'. In: Lombard, P., (ed.). Bahrain. The Civilization of the Two Seas, from Dilmun to Tylos (Catalogue of the Exhibition held at the Institut du Monde Arabe, Paris, May-August 1999), Éditions IMA and SDZ, Paris and Gent, pp. 33-36.

Dexter Lord, G. and Blankenberg. N. (eds) (2015). Cities, Museums and Soft Power. Washington DC: The AAM Press.

Durand, E.L. (1880). 'Extracts from Report on the Islands and Antiquities of Bahrain'. Journal of the Royal Asiatic Society, 12: pp.1-39.

Erskine-Loftus, P. (2010). 'A Brief Look at the History of Museums in the Region and Wider Middle East'. 2A Architecture and Art, 13: pp.18-20.

Erskine-Loftus, P. (2016). 'Displaying in the Peninsula: Museums as Creators of a Visual identity'. In: Mounajjed, N. (ed.). Visual Culture(s) in the Gulf: An Anthology. Cambridge: Gulf Research Centre. pp.71-90.

Erskine-Loftus, P., Hightower, V. and Al-Mulla, M. (eds) (2016). Representing the Nation. Heritage, Museums, National Narratives and Identity in the Arab Gulf States. Abington and New York: Abingdon.

Exell, K. and Rico, T. (2014). Cultural Heritage in the Arabian Peninsula, Debates, Discourses and Practices. Farnham: Ashgate.

Exell, K. and Wakefield, S. (2016). Museums in Arabia. Transnational Practices and Regional Processes. Abington and New York: Routledge.

Ghosh, A. (1968) . Protection of Cultural Property and Development of a Museum in Bahrain. Restricted Report $\mathrm{n}^{\circ}$ 787/BMS.RD/CLT, UNESCO, Paris. 
Harrison, R. (2013). Heritage: Critical Approaches. Abingdon and New York: Routledge.

Holscher, K. (1990). 'The National Museum of Bahrain'. Minar: Architecture in Development, 35: pp.24-29.

Højlund, F. (2007). The Burial Mounds of Bahrain. Social complexity in Early Dilmun. Højbjerg and Bahrain: Jutland Archaeological Society and Ministry of Information, Bahrain.

Kinoshita, H. (2014). 'How the strategies of cultural diffusion build a museum territory'. Museologica Brunensia, Vol 3: pp.14-23.

Laursen, S.T. (2017). The Royal Mounds of A'ali in Bahrain. The Emergence of Kingship in Early Dilmun. Højbjerg: Jutland Archaeological Society.

Lombard, P. (2016a). 'L'archéologie du royaume de Bahreïn aujourd'hui, entre avancées et inquiétudes'. Routes de l'Orient, Hors série 3: pp.117-138.

Lombard, P., (ed.). (2016b). Qal'at al-Bahrain, Ancient Harbour and Capital of Bahrain. The Site Museum. Manama: Bahrain Authority for Culture and Antiquities.

Lombard, P. (2018). 'The Qal'at al-Bahrain Site Museum. An interpretation of the World Heritage inscription criteria'. World Heritage 88: pp.26-29.

Lombard, P., and Al-Sindi, K. (1999). 'Bahrain: Two Seas, One Civilization'. In: Lombard, P. (ed). Bahrain. The Civilization of the Two Seas, from Dilmun to Tylos (Catalogue of the Exhibition held at the Institut du Monde Arabe, Paris, May-August 1999), Paris and Gent: Éditions IMA and SDZ, pp.22-27.

MacLean, R., and Insoll, T. (2014). 'Islamic Identities and Heritage Presentation in Bahrain'. In: Exell, K. and Rico, T. (eds.). Cultural Heritage in the Arabian Peninsula. Debates, Discourses and Practices. Farnham: Ashgate. pp.129-141.

MacLean, R., and Insoll, T. (2011). An Archaeological Guide to Bahrain. Oxford: Archaeopress.

Musameh, A. (2004). The Way to Dilmun. 50 Years of Searching and Excavating. Manama: Ministry of Information.

Musameh, A. (1999). The Bahrain National Museum. Manama: Ministry of Information. (Arabic) 
Potts, D.T. (1990). The Arabian Gulf in Antiquity, I. From Prehistory to the Fall of the Achaemenid Empire. Oxford: Clarendon Press.

Rawlinson, H. (1880). 'Notes on Capt. Durand's Report upon the Islands of Bahrein'. Journal of the Royal Asiatic Society: 12: pp. 200-227.

Rice, M., (ed.). (1984). Dilmun Discovered. The Early Years of Archaeology in Bahrain. London: Longman.

Saidah, R., Lewcock, R.B. (1980). 'Bahrain. Conservation, Restoration and Presentation of Archeological Monuments and Sites of the Pre-Islamic and Islamic Periods'. Restricted Technical Report $n^{\circ} \mathrm{FMR} / \mathrm{CC} / \mathrm{CH} / 152$, UNESCO: Paris.

Smith, L. (2006). Uses of Heritage. Abington and New York: Routledge.

Tjahjono, G. (1995). The National Museum of Bahrain. Technical Review Summary. Unpublished Report.

Vine, P. (1993). Bahrain National Museum. London: Immel Publishing.

Wakefield, S. (2015). 'Museum Development in the Gulf: Narrative and Architecture'. Architecture Design, vol. 85: pp.20-27.

\section{NOTES}

${ }^{1}$ The Danish archaeological mission was affiliated with the Moesgård Museum near Aarhus, and led by archaeologists P. V. Glob and G. Bibby.

2 The Bahrain Historical and Archaeological Society is an NGO that was founded in 1953 and that played an important role in disseminating knowledge about Bahrain's longstanding past.

3 The authors are grateful to Ms Fidaa Al-Zaidany, head of Studies and Research at BACA, for assisting with research and compiling archival material and staff reports relating to the creation of the Bahrain National Museum.

${ }^{4}$ The number of museum visitors during the first year (1989) was 77,702. The visitors' number increased to 109,945 in 1993 and 153,425 in 1994. 
${ }^{5}$ Previously Culture and National Heritage Sector within the Ministry of Information, then Ministry of Culture and Information (2009 - 2013) and Ministry of Culture (2013 - 2015).

6 'Perles de Bahreïn' (Paris, 1999) and 'Bahreïn, la Civilisation des Deux Mers' (Paris, 1999, then renamed 'Traces of Paradise' - London, 2000 - and 'Unbekanntes Paradies' - Dresden, 2000-2001) were the debut of an active cultural strategy to place Bahrain on the international cultural map. In 2012, 'Tylos, the journey beyond life' showcased at the State Hermitage Museum in St. Petersburg and the State Oriental Museum in Moscow paved the way for important international collaborations with Russia, France, Turkey, Morocco, Italy and the United States (see also Aubry this volume).

${ }^{7}$ As the head of the French Archaeological Mission at Qal'at al-Bahrain site since 1989, Pierre Lombard was directly involved in the inception, development and curation of the museum.

${ }^{8}$ In 2007, Shaikha Mai bint Mohamed Al-Khalifa launched the Investing in Culture initiative to encourage the private sector to invest in public cultural projects.

9 The Pearling, Testimony of an Island Economy, a UNESCO World Heritage Site, is a serial nomination consisting of 15 property components in Muharraq. The path reflects the final expression and last remaining example of a cultural tradition that dominated the Arabian Gulf from prehistory to the early $20^{\text {th }}$ century. 